Full length article

\title{
Phase constitution and microstructure of the NbTiVZr refractory high-entropy alloy solidified upon different processing
}

\author{
Angelo F. Andreoli ${ }^{\mathrm{a}, *}$, Rafael G. Mendes ${ }^{\mathrm{a}, \mathrm{b}}$, Victor T. Witusiewicz ${ }^{\mathrm{c}}$, Olga Shuleshova ${ }^{\mathrm{a}}$, \\ Marijn A. van Huis ${ }^{\mathrm{b}}$, Kornelius Nielsch ${ }^{\mathrm{d}, \mathrm{e}}$, Ivan Kaban ${ }^{\mathrm{a}, *}$ \\ a IFW Dresden, Institute for Complex Materials, Helmholtzstr. 20, 01069, Dresden, Germany \\ ${ }^{\mathrm{b}}$ Soft Condensed Matter, Debye Institute for Nanomaterials Science, Utrecht University, Princetonplein 5, 3584 CC Utrecht, the Netherlands \\ ${ }^{\mathrm{C}}$ ACCESS e.V., Inzestraße 5, 52072, Aachen, Germany \\ d IFW Dresden, Institute for Metallic Materials, Helmholtzstraße 20, 01069, Dresden, Germany \\ ${ }^{\mathrm{e}}$ Institute of Materials Science, Technische Universität Dresden, 01062, Dresden, Germany
}

\section{A R T I C L E I N F O}

\section{Article history:}

Received 5 July 2021

Revised 13 October 2021

Accepted 13 October 2021

Available online 21 October 2021

\section{Keywords:}

High-entropy alloy

Undercooling

Metastable solidification

Growth kinetics

Microstructure

\begin{abstract}
A B S T R A C T
Time- and temperature-resolved phase formation in the equiatomic NbTiVZr refractory high-entropy alloy has been studied in situ using high-energy synchrotron X-ray diffraction and high-speed video imaging during non-equilibrium solidification. Phase formation is shown to be dependent on the solidification conditions. When the melt is undercooled over $80 \mathrm{~K}$ it crystallizes as a bcc single-phase solid solution despite solute partitioning between dendrites and interdendritic regions. When the sample is for some time kept in the semisolid state, two additional bcc phases form in the interdendritic regions. The crystal growth velocity for the NbTiVZr alloy, as estimated from the high-speed videos, shows pronounced sluggish kinetics.
\end{abstract}

(c) 2021 The Author(s). Published by Elsevier Ltd on behalf of Acta Materialia Inc. This is an open access article under the CC BY-NC-ND license (http://creativecommons.org/licenses/by-nc-nd/4.0/)

\section{Introduction}

The search for materials suitable for high-temperature and radiation-resistant applications gained a new perspective with the introduction of refractory high-entropy alloys (RHEAs) [1]. This design concept opens new avenues for exploring a compositional space based on the high melting temperature metallic elements (W, Ta, Mo, Nb, Hf, V, Zr). At the same time, it brings challenges in investigations of the phase formation and stability ranges, mechanical properties, and corrosion resistance under such extreme thermal conditions. Resolving these key material properties is required to cross the bridge between scientific enthusiasm and practical applications.

The NbTiVZr equiatomic composition was proposed as a low density $\left(\rho=6.52 \mathrm{~g} \cdot \mathrm{cm}^{-3}\right)$ RHEA $[2,3]$, showing good compressive ductility and strong work hardening behavior at room temperature. The compression yield strength data for this alloy at the high-temperature regime are scattered. Jia et al. [4] reported that

\footnotetext{
* Corresponding authors.

E-mail addresses: a.fernandes.andreoli@ifw-dresden.de (A.F. Andreoli), i.kaban@ifw-dresden.de (I. Kaban).
}

the strength of this alloy reached a maximum of $500 \mathrm{MPa}$ and then stabilized at $200 \mathrm{MPa}$ during compression testing at $1273 \mathrm{~K}$. On the other hand, low yield strengths of $75 \mathrm{MPa}$ and $58 \mathrm{MPa}$ at $1273 \mathrm{~K}$ were reported in Refs. [3] and [5], respectively. This perhaps limits its use for high-temperature applications, but it does not exclude service at moderate temperatures [6]. King et al. [6] used a high throughput computational tool, Alloy Search and Predict, to screen over one million four-component equiatomic compositions, looking for those which would form a single-phase solid solution (SPSS) at the melting point and have a low thermal neutron absorption cross-section. The NbTiVZr alloy was found to comply with both requirements.

The available publications on the NbTiVZr RHEA report on different phases and microstructures, depending on the fabrication and processing route. Senkov et al. [2] produced NbTiVZr samples by arc-melting followed by hot isostatic pressing at $1473 \mathrm{~K}$ and $207 \mathrm{MPa}$ for 2 hours. In sequence, the alloy was homogenized at $1473 \mathrm{~K}$ for 24 hours and cooled with a low rate of $10 \mathrm{~K} \cdot \mathrm{min}^{-1}$. The microstructure was composed of large grains $(\sim 600 \mu \mathrm{m})$ with a body-centered cubic (bcc) crystal structure matrix and homogeneously distributed $\mathrm{Zr}$-rich regions of $20-30 \mu \mathrm{m}$ inside the grains and sub-micron $\mathrm{V}$-rich particles inside the $\mathrm{Zr}$-rich regions. 
Table 1

Measured chemical composition of the NbTiVZr as-cast alloy.

\begin{tabular}{ll}
\hline Element & Concentration (at. \%) \\
\hline $\mathrm{Nb}$ & $24.80 \pm 0.17$ \\
$\mathrm{Ti}$ & $24.90 \pm 0.10$ \\
$\mathrm{~V}$ & $24.80 \pm 0.15$ \\
$\mathrm{Zr}$ & $24.40 \pm 0.45$ \\
$\mathrm{Hf}$ & $0.3 \pm 0.00$ \\
\hline
\end{tabular}

The crystal structure of the precipitates could not be identified with X-ray diffraction (XDR) due to their small volume fraction. Yurchenko et al. [7] had also found a small fraction of a second phase at the grain boundaries in NbTiVZr samples homogenized at the same conditions and and observed a splitting of the (110) bcc peak on the measured X-ray diffraction (XRD) curves.

In contrast, only one bcc phase was found in a NbTiVZr sample prepared by arc-melting of pure components in the work of Tong et al. [8] as well as in a homogenized (1473 K, 100 hours) and water-quenched alloy in the study of King et al. [6]. However, after a subsequent aging at $973 \mathrm{~K}$ for 100 hours, the bcc SPSS decomposed into a bcc matrix and hexagonal closed-packed ( $h c p)$ and $\mathrm{V}_{2} \mathrm{Zr}$ (C15-Laves) minor phases [6].

Senkov et al. [5] reported on the appearance of three bcc phases after compression deformation of the NbTiVZr alloy with initial SPSS $b c c$ structure at $1273 \mathrm{~K}$. It was suggested that there exists a miscibility gap in the NbTiZrV composition, which results in the decomposition of the high-temperature bcc phase below $1673 \mathrm{~K}$.

As it has been demonstrated for many HEAs [9-12], processing conditions and kinetics play an important role in determining the final microstructures. A challenge in the study of refractory materials is that high-temperature measurements are usually difficult due to instrumentation limits. For example, measurement of the liquidus $\left(T_{1}\right)$ and solidus $\left(T_{S}\right)$ temperatures cannot be done using conventional differential scanning calorimetry. On the other hand, sample levitation techniques, such as electromagnetic levitation (EML) used in the present work, allow for processing and investigations even in the liquid state.

This study aims at elucidating phase formation and microstructure development upon solidification and during heating/cooling of the NbTiVZr RHEA. A better understanding of metastability, temperature-dependent phase transformations, and the role of kinetics is required for a proper choice of the processing parameters during fabrication and potential use of this material in hightemperature and/or radiation-resistant applications.

\section{Materials and methods}

Spherical-like samples of the NbTiVZr alloy (about 0.55 - $1 \mathrm{~g}$ weight) were produced from pure elements (Ti $99.99 \%$; $\mathrm{Nb}, \mathrm{Zr}$ and V $99.8 \%$ ) by arc-melting in a water-cooled copper hearth. The furnace was previously evacuated to $5 \cdot 10^{-5}$ mbar and backfilled with Ar up to a pressure of 600 mbar. At least four melting cycles were repeated to achieve chemical homogeneity. A high-purity Ti button (about $10 \mathrm{~g}$ weight) placed in the furnace and heated by electric arc was used as an oxygen getter.

The chemical composition of an as-cast sample determined by inductively coupled plasma optical emission spectrometry (ICPOES) using an iCAP 6500 Duo View from Thermo Fischer Scientific is given in Table 1 . The element concentrations deviated by 0.1 to 0.6 at. \% from the nominal composition. It should be mentioned that 0.3 at. \% of hafnium was also detected in the specimens. The origin of this impurity should be the raw $\mathrm{Zr}$ rod. Hf and $\mathrm{Zr}$ have the same crystal structure, comparable electronegativity, atomic radius, and similar physical properties [13], which leads us to believe that the small amount of $\mathrm{Hf}$ will not influence the results of this study.

The mobile EML facility of the IFW Dresden [14] was used to carry out the solidification experiments. The samples were levitated and inductively heated using a specially designed watercooled coil made of copper tube with an inner diameter of 1 $\mathrm{mm}$ and an outer diameter of $2 \mathrm{~mm}$. A high-frequency generator TruHeat HF 3010 from Hüttinger Elektronik (10 kW) was operated at $280 \mathrm{kHz}$. The experimental chamber was evacuated to better than $5 \cdot 10^{-6}$ mbar and backfilled with high purity $\mathrm{He}(6 \mathrm{~N})$ to 500 700 mbar. The sample cooling was done by two He gas jets (6N purity) directed to the sample surface from opposite sides with a flow of up to $28 \mathrm{l} \cdot \mathrm{min}^{-1}$. A one-color pyrometer, $50 \mathrm{~Hz}$ sampling rate, was used for recording temperature-time profiles during sample processing.

In situ synchrotron XRD experiments were carried out at the broadband diffraction beamline P21.1 at the PETRA III synchrotron source at the German Electron Synchrotron DESY, Hamburg. A hybrid pixel PILATUS3 X 2M CdTe detector (DECTRIS) at a sampling rate of $20 \mathrm{~Hz}$ was used to acquire the diffracted intensity in transmission mode. The recorded 2D images were azimuthally integrated with the FIT2D software [15], to obtain XRD intensities as functions of the diffraction vector $Q=4 \pi \sin \theta / \lambda$, where $2 \theta$ is the diffraction angle and $\lambda$ is the wavelength $(0.122 \AA$ in the present work).

Estimation of dendrite growth velocities $v$ was done by measuring the recalescence front travel distances observed from the in situ high-speed videos (HSV) (FASTCAM SA5, 775K-M3, from Photron), measured at 1000 frames per second during crystallization. Traveled distances in pixels were converted to length by using the conversion factor of $68 \mathrm{px} \cdot \mathrm{mm}^{-1}$, which was determined using a standard sample during unit calibration. The videos were analyzed with the Fiji ImageJ software [16]. More details on data analysis can be found in Ref. [17].

Metallographic specimens were prepared using standard grinding techniques and fine polishing with colloidal silica $(0.05 \mu \mathrm{m})$ suspension. The microstructural examination was performed using a ZEISS Gemini field emission scanning electron microscope (SEM) equipped with a backscattered electron (BSE) detector and an energy-dispersive X-ray (EDX) detector.

Transmission electron microscopy (TEM) samples were prepared as follows. Firstly, slices cut out from the middle of the samples processed in the EML were thinned by grinding down to $\sim 100$ $\mu \mathrm{m}$. Then, thin cross-sections in the range of approximately 50-80 $\mathrm{nm}$ (electron-transparent) were obtained from the ground samples by ion beam milling using a focussed ion beam (FIB) in the SEM. The thin cross-sections were fixed onto a TEM grid and placed in a TEM single-tilt holder. The measurements were carried out using a FEI F30 TEM operating in a conventional mode at an accelerating voltage of $300 \mathrm{kV}$ and a Thermo Fisher Scientific Talos F200X operating in conventional and scanning modes at an accelerating voltage of $200 \mathrm{kV}$. The TEM images were analyzed and processed using the FEI TEM Imaging and Analysis, Thermo Fisher Scientific Velox, and the Gatan Digital Micrograph software. The selected area electron diffraction (SAED) patterns were indexed using the program ELDISCA C\# [18].

Room temperature XRD was measured, on the slices cut from the solidified samples, at the P21.1 beamline at DESY (beam crosssection: $\left.1 \times 1 \mathrm{~mm}^{2}, \lambda=0.122 \AA\right)$. The diffraction patterns were analyzed using the X'Pert HighScore Plus program [19] and the lattice parameters were calculated with the UnitCell software [20].

Lever rule thermodynamic calculations and Scheil-Gulliver solidification simulation were performed using the Thermo-Calc 2020a software from Thermo-Calc AB [21] and the TCHEA4 database [22]. In both cases, all phases modeled in the TCHEA4 relating to the $\mathrm{Nb}-\mathrm{Ti}-\mathrm{V}-\mathrm{Zr}$ system were entered. 

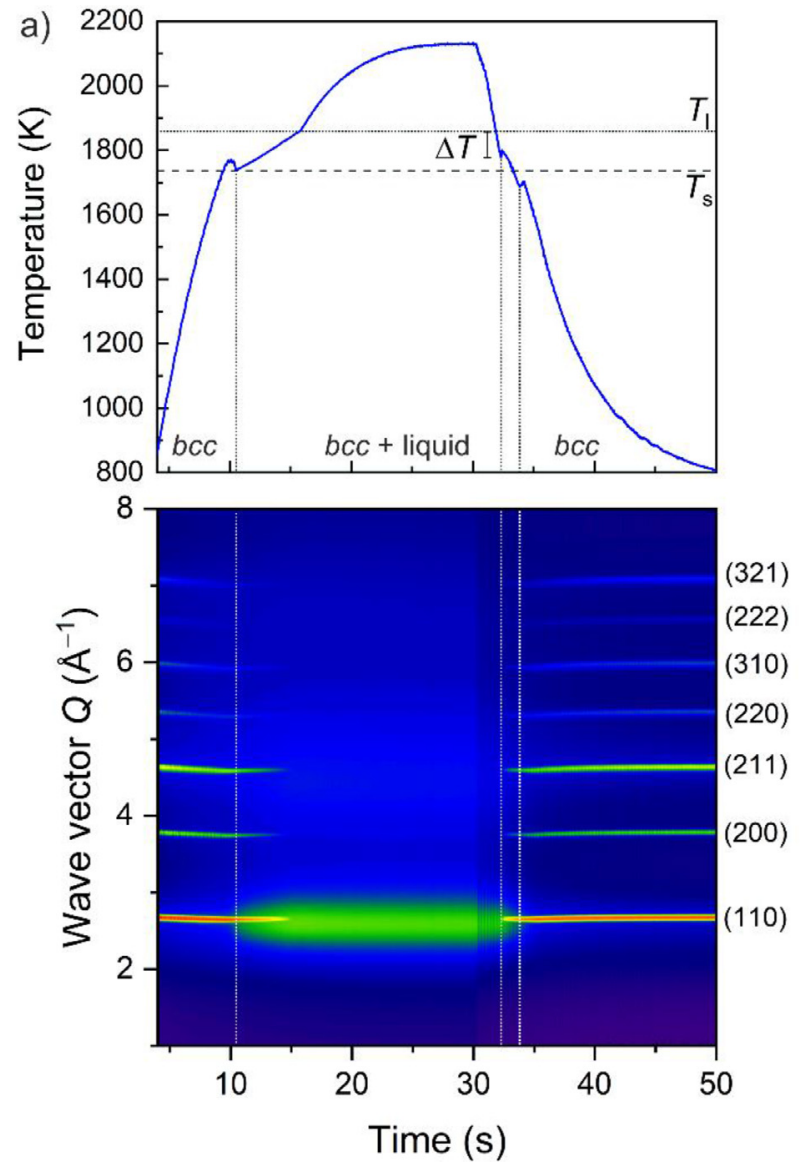
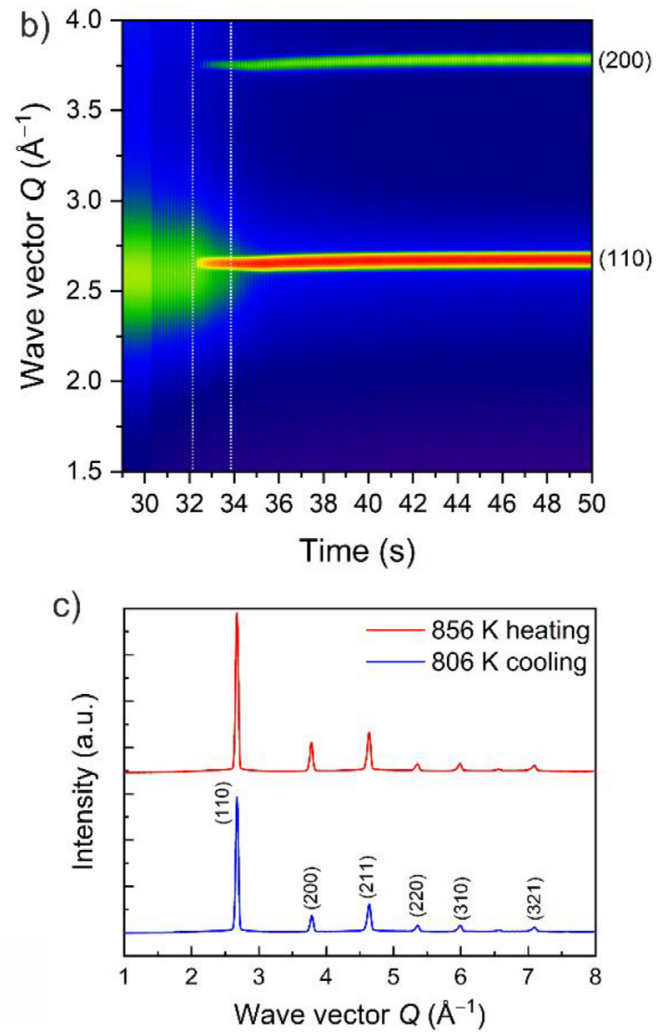

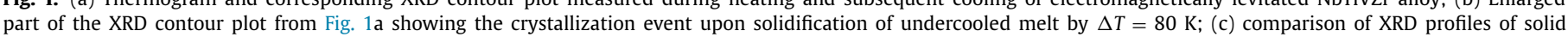
NbTiVZr alloy at the initial and final stages of EML processing.

\section{Results}

\subsection{In situ synchrotron X-ray diffraction}

Fig. 1a shows a temperature-time profile measured during a heating/cooling cycle, coupled with the time-resolved XRD patterns plotted as a color-contour diagram. The pyrometer was calibrated using the melting point of pure vanadium observed on the thermogram measured in the EML facility, at the same processing conditions. Thermal analysis using a calorimeter was not possible since NbTiVZr samples reacted with both $\mathrm{Al}_{2} \mathrm{O}_{3}$ and $\mathrm{ZrO}_{2}$ crucibles. The solidus and liquidus temperatures for the NbTiVZr alloy were registered during 16 heating/cooling cycles carried out in the EML facility, and the average temperature and standard deviation were calculated (Table 2). The values of $T_{\mathrm{S}}$ and $T_{1}$ from the thermodynamic calculations are also included in Table 2.

In Fig. 1a, a peak appearing at $1766 \mathrm{~K}$ on the thermogram measured during heating is due to a change of emissivity upon the onset of melting. The solidus temperature is registered as $1736 \mathrm{~K}$.

Table 2

The solidus $T_{\mathrm{S}}$ and liquidus $T_{\mathrm{l}}$ temperatures of the $\mathrm{NbTiVZr}$ RHEA measured with a one-color pyrometer during heating in the EML facility and calculated using the ThermoCalc AB software and the TCHEA4 database.

\begin{tabular}{lll}
\hline & $T_{\mathrm{S}}(\mathrm{K})$ & $T_{1}(\mathrm{~K})$ \\
\hline Experimental & $1736 \pm 12$ & $1858 \pm 7$ \\
CALPHAD & 1762 & 1926 \\
\hline
\end{tabular}

During heating up to $T_{\mathrm{S}}$ only XRD peaks corresponding to a bcc crystal structure can be identified. The melting ends at $1858 \mathrm{~K}$ and the liquid is further overheated by approximately $300 \mathrm{~K}$ above $T_{1}$. During this stage, only diffuse scattering is measured, confirming that the alloy is completely molten. The liquid is then cooled by decreasing the input power to the induction coil and by two jetstreams of He directed to the sample's surface by opposite sides. At $1778 \mathrm{~K}$ spontaneous nucleation is recorded by the pyrometer which yields a liquid undercooling of $\Delta T=80 \mathrm{~K}$. The XRD peaks that appear following this stage correspond to a bcc crystal structure. Fig. 1c shows the X-ray diffractograms for this particular cycle at two distinct temperatures; during heating at $856 \mathrm{~K}$ and cooling at $806 \mathrm{~K}$. It is clear from the patterns that the initial and final states show the same $(b c c)$ structure. A 3D XRD plot corresponding to the crystallization of the sample is shown in Fig. S1 in Supplementary Materials.

Fig. 2a shows a temperature-time profile coupled with the time-resolved XRD patterns for a NbTiVZr sample heated up close to the liquidus temperature, but without reaching a complete melting. This is seen from the (110), (200), and (211) peaks that extend throughout the whole duration of the experiment. During heating from room temperature up to $T_{\mathrm{s}}$, only diffraction peaks that are indexed to a $b c c$ structure are recognizable. In the semisolid state, between about $15 \mathrm{~s}$ and $75 \mathrm{~s}$, Bragg peaks of the bcc phase overlap with the diffuse peaks scattered by the liquid phase, see for example the XRD pattern at $1830 \mathrm{~K}$ and $\sim 56 \mathrm{~s}$ in Fig. $2 \mathrm{c}$.

Upon the sample cooling, starting from approximately $75 \mathrm{~s}$, reflections of several crystalline phases are observed in the XRD patterns, see the enlarged plot in Fig. $2 \mathrm{~b}$. These peaks are indexed to 

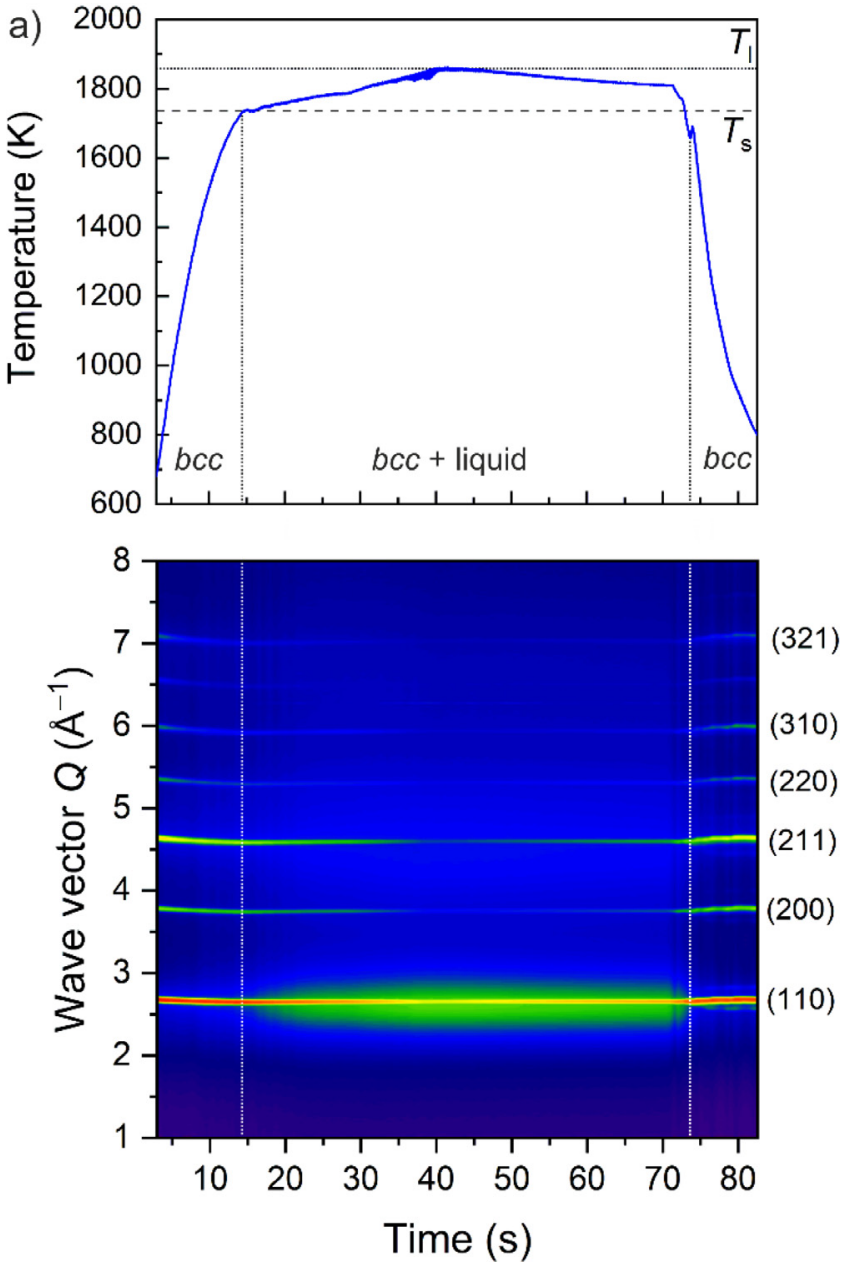

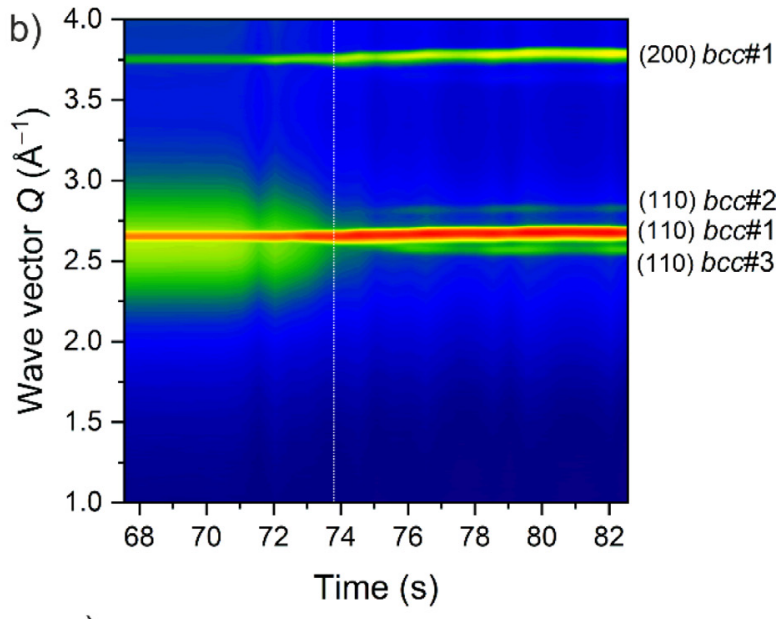

c)

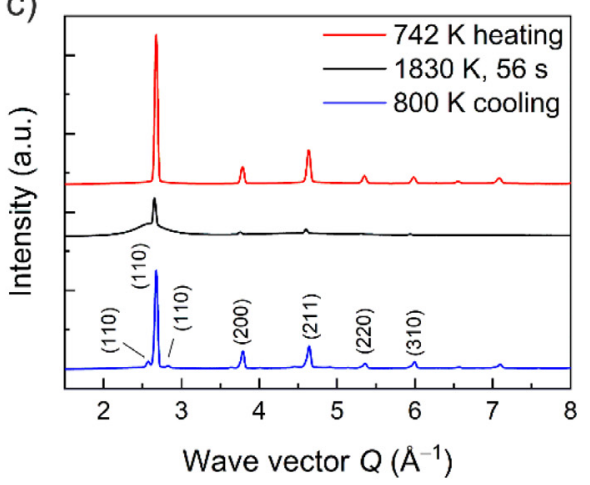

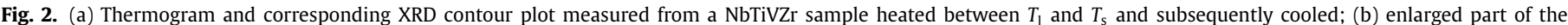
XRD contour plot from Fig 2a showing the appearance of different diffraction peaks upon cooling; (c) comparison of XRD profiles at different stages of EML processing.

two extra bcc phases. The onset temperature for the appearance of the bcc\#2 is $1491 \mathrm{~K}$ and the onset temperature for the bcc\#3 phase is $1281 \mathrm{~K}$. A small peak on the temperature-time profile around $74 \mathrm{~s}$ (Fig. 2a) corresponds to a change of the emissivity of the alloy upon crystallization. A 3D XRD plot measured during cooling of this sample is shown in Fig. S2 in supplementary materials.

The samples were always weighed before and after the levitation experiments and the maximum weight loss was $\sim 0.01 \mathrm{wt}$. $\%$. This indicates that neither oxidation nor crucial compositional changes occurred.

\subsection{Room temperature synchrotron X-ray diffraction}

Fig. 3 displays the ex situ synchrotron XRD measurements of the samples shown in Figs. 1 and 2 after solidification. In Fig. 3a only peaks corresponding to a bcc SPSS (bcc\#1) are seen. In Fig. $3 \mathrm{~b}$ besides the peaks corresponding to the primary bcc phase (bcc\#1), additional (111) reflections are marked for $b c c \# 2$ and bcc\#3 phases. Fig. 3c shows the same pattern as in Fig. $3 \mathrm{~b}$ but with a reduced scale of intensity, so the weaker reflections from other crystallographic planes are distinguishable. The lattice parameters extracted from the XRD curve are $0.330 \mathrm{~nm}, 0.312$ $\mathrm{nm}$ and $0.344 \mathrm{~nm}$ for the $b c c \# 1, b c c \# 2$ and $b c c \# 3$ phase, respectively. These values are in a good agreement with those of the three $b c c$ phases found in the NbTiVZr alloy after high-temperature compression test by Senkov et al. [5]: $0.332 \mathrm{~nm}, 0.324 \mathrm{~nm}$ and $0.345 \mathrm{~nm}$

\subsection{High-speed video imaging}

Digital images representing the solidification of a NbTiVZr melt at an undercooling of $107 \mathrm{~K}$ are shown in Fig. 4a. In the upper left panel, the melt at its maximum undercooling is seen. In the uppermiddle panel, a phase can be observed (brighter contrast) growing in the liquid (darker contrast). The remaining panels show the sequence of the crystallization process. The difference in the contrast is due to the release of latent heat from the crystallizing solid. In Fig. $4 \mathrm{~b}$ the variation of the images' grayscale level, measured on a $50 \times 50$ pixel area in the central part of a sample in the videos, is shown as a function of time during the crystallization of the liquid. The grayscale dataset is smoothened because the crystallization is slower than the rotation of the sample. This makes either the liquid or solid phase to be within the analyzed area in a certain period of time. Therefore, a periodic pattern of the grayscale is observed especially once the crystallization starts. The video is available in Supplementary Materials (Video 1).

\subsection{Microstructure and structure analysis}

SEM micrographs recorded using the BSE detector, combined with the corresponding EDX elemental maps, are displayed in Figs. $5 a$ and $5 b$ for the sample shown in Fig. 3a. Fig. 5a shows a dendritic microstructure with solute rejection to interdendritic regions (brighter contrast). From the EDX elemental mappings, it is possible to observe that the dendrite cores are rich in $\mathrm{Nb}$ and 

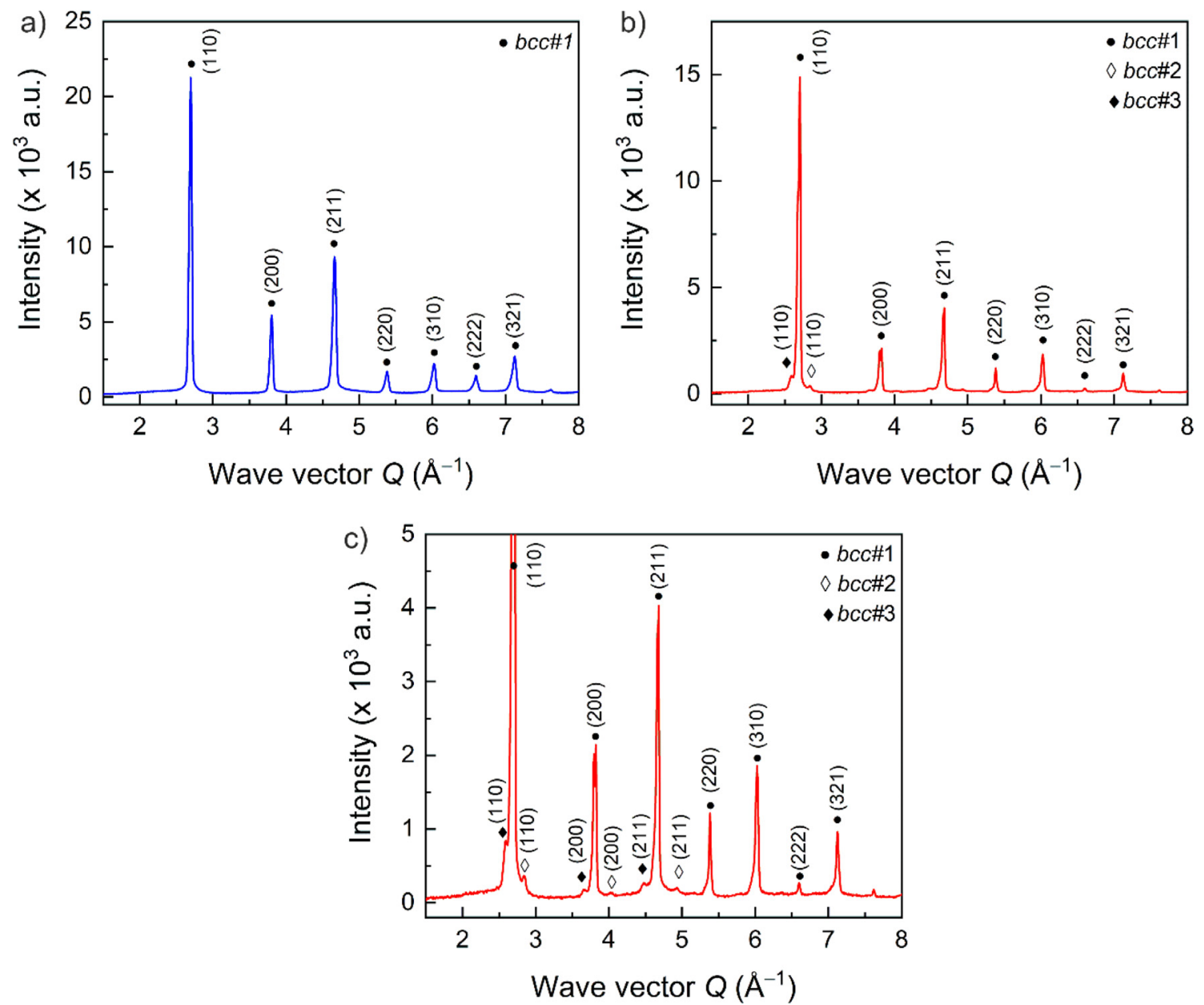

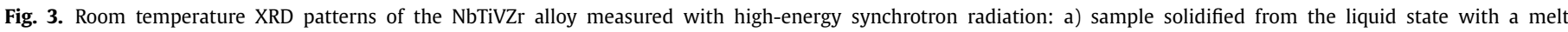

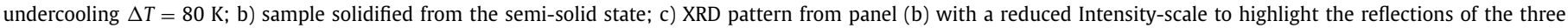
bcc phases.

Ti, while they are depleted of $\mathrm{Zr}$ and $\mathrm{V}$. Despite the evident microsegregation (Fig. 5b), no second phase can be recognized from the SEM image (Fig. 5a) which is in agreement with the in situ (Fig. 1) and ex situ synchrotron XRD measurements in Fig. 3a.

In Fig. 5c, a dendritic microstructure, which is much coarser than that shown in Fig. 5a, is observed with three different contrast regions from the SEM-BSE image: i) a medium-bright region corresponding to the matrix, ii) a brighter region along the grain boundaries, and iii) submicron-sized dark particles inside the latter. The SEM-EDX mappings show that the matrix, $b c c \# 1$ in the $\mathrm{XRD}$ profile in Fig. $3 \mathrm{~b}$, is rich in $\mathrm{Nb}$ and $\mathrm{Ti}$, while depleted of $\mathrm{Zr}$ and $\mathrm{V}$. The bright regions along the grain boundaries seen in the SEM-BSE image (Fig. 5c) are enriched with $\mathrm{Zr}$ and $\mathrm{V}$, and the dark particles are rich with vanadium. SEM and EDX images with higher magnification are shown in Fig. S3 in Supplementary Material. The crystal structure of the precipitates was further investigated by TEM.

Fig. 6a shows a SEM-BSE image of the dendritic microstructure of a sample solidified with a melt undercooling of $80 \mathrm{~K}$, as illustrated in Fig. 5a. The red line marks the area from which a FIB-SEM cross-section for further TEM investigations was prepared. A low magnification TEM image of the prepared cross-section is shown in Fig. 6b. Multiple SAED measurements were acquired to confirm the presence of a single $b c c$ phase. Typical electron diffractograms for different regions of the sample are shown in Fig. $6 \mathrm{c}$ and Fig. $6 \mathrm{~d}$. The diffraction patterns were indexed as a bcc phase with a lattice parameter of $0.330 \mathrm{~nm}$ corresponding to the lattice parameter determined from the synchrotron XRD at room temperature (Fig. 3a). All patterns were indexed corresponding to the (111) zone axis. Fig. 6e shows images of the cross-sectional specimens collected with a high-angle annular dark-field (HAADF) detector with the TEM operating in the scanning mode (STEM). STEM is a variation of TEM that uses a focused electron beam that is scanned over a thin specimen. STEM-HAADF imaging allows the differentiation between different atomic elements as in this imaging mode, the intensity scales with approximately the atomic number squared $(I \sim$ $Z^{2}$ ). STEM also makes it possible to probe the local chemical composition of the specimen using the EDX detector. STEM-EDX mappings of different regions of the sample (Fig. $6 \mathrm{f}$ and Fig. $6 \mathrm{~g}$ ) show the homogeneous nature of the sample. A thorough investigation of the cross-section was carried out with high-resolution images and multiple regions for SAED were acquired and are presented in Supplementary Material (Figs. S4 and S5).

Fig. 7 shows images of a sample processed from the semisolid state, as illustrated in the XRD pattern in Fig. 3b. The SEM-BSE image is shown in Fig. 7a. To investigate these three regions in detail, a cross-section indicated by the red line in Fig. 7a has been studied by TEM. Low magnification and high magnification TEM images depicting the different regions of interest are shown in Fig. 7b and Fig. 7c, respectively. Figs. $7 \mathrm{~d}$ and $7 \mathrm{e}$ show electron diffraction patterns corresponding to the $b c c$ matrix (lattice parameter: 0.330 $\mathrm{nm})$. A thorough study of the matrix was also conducted in this 

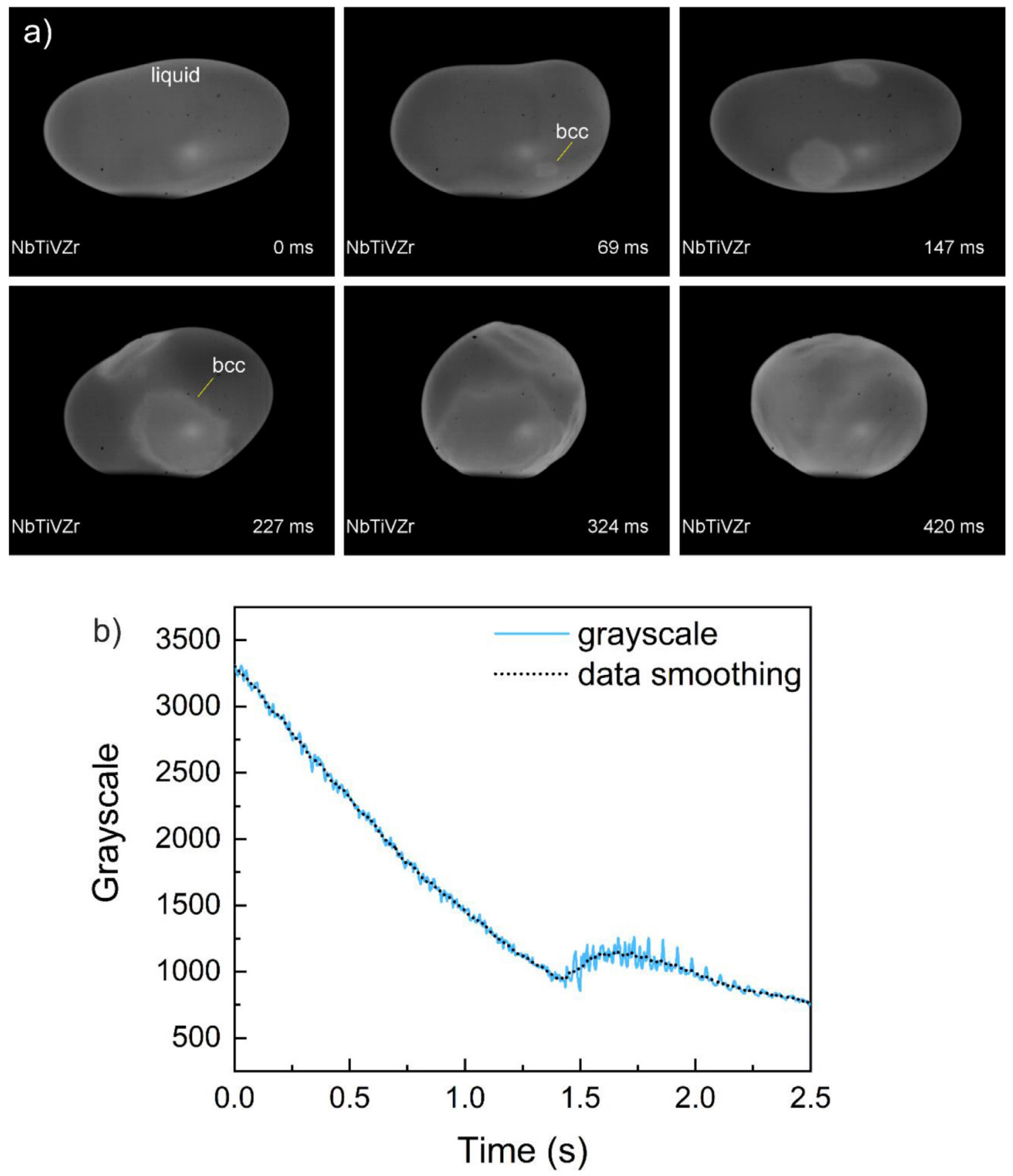

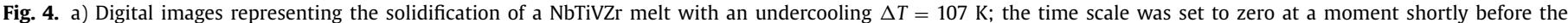
onset of crystallization; b) variation of the grayscale level on a $50 \times 50$ pixel area as a function of time measured in the central part of the sample shown in panel (a).

case with a high-resolution image and multiple SAED patterns and is presented in Supplementary Material (Fig. S6). Fig. 7f shows a diffraction pattern on the interface between the Zr-rich region (lattice parameter: $0.344 \mathrm{~nm}$ ) and the V-rich region (lattice parameter: $0.312 \mathrm{~nm}$ ), where it is possible to distinguish two different diffraction points. Fig. $7 \mathrm{~g}$ presents the diffraction pattern of the $\mathrm{V}$ rich particles (lattice parameter: $0.312 \mathrm{~nm}$ ). All patterns were indexed corresponding to the (100) zone axis of a bcc crystal structure, showing that all grains and interfaces are aligned in the same $b c c$ superstructure. The EDX elemental mapping of the different regions depicted in the HAADF image (Fig. $7 \mathrm{~h}$ ) shows that $\mathrm{Nb}, \mathrm{Zr}$, $\mathrm{Ti}$, and $\mathrm{V}$ are homogeneously distributed in the matrix (Fig. 7i), whereas Fig. $7 \mathrm{j}$ clearly shows the $\mathrm{V}$-rich and $\mathrm{Zr}$-rich regions at the grain boundaries. This is in agreement with the EDX maps ob- tained with SEM (Fig. 5d). High-resolution images of all phases are presented in the Supplementary Materials (Fig. S7), while the elemental mapping images of higher magnifications are presented in Fig. S8.

\section{Discussion}

\subsection{Phase formation upon solidification}

To the best of our knowledge, no experimental values of $T_{\mathrm{S}}$ and $T_{1}$ have been reported in the literature for this RHEA. This is supposedly due to the reactivity of this alloy with the crucible materials during DTA experiments at high temperatures, as observed in the present work. The solidus temperature $T_{\mathrm{S}}=1736 \pm 12 \mathrm{~K}$ 

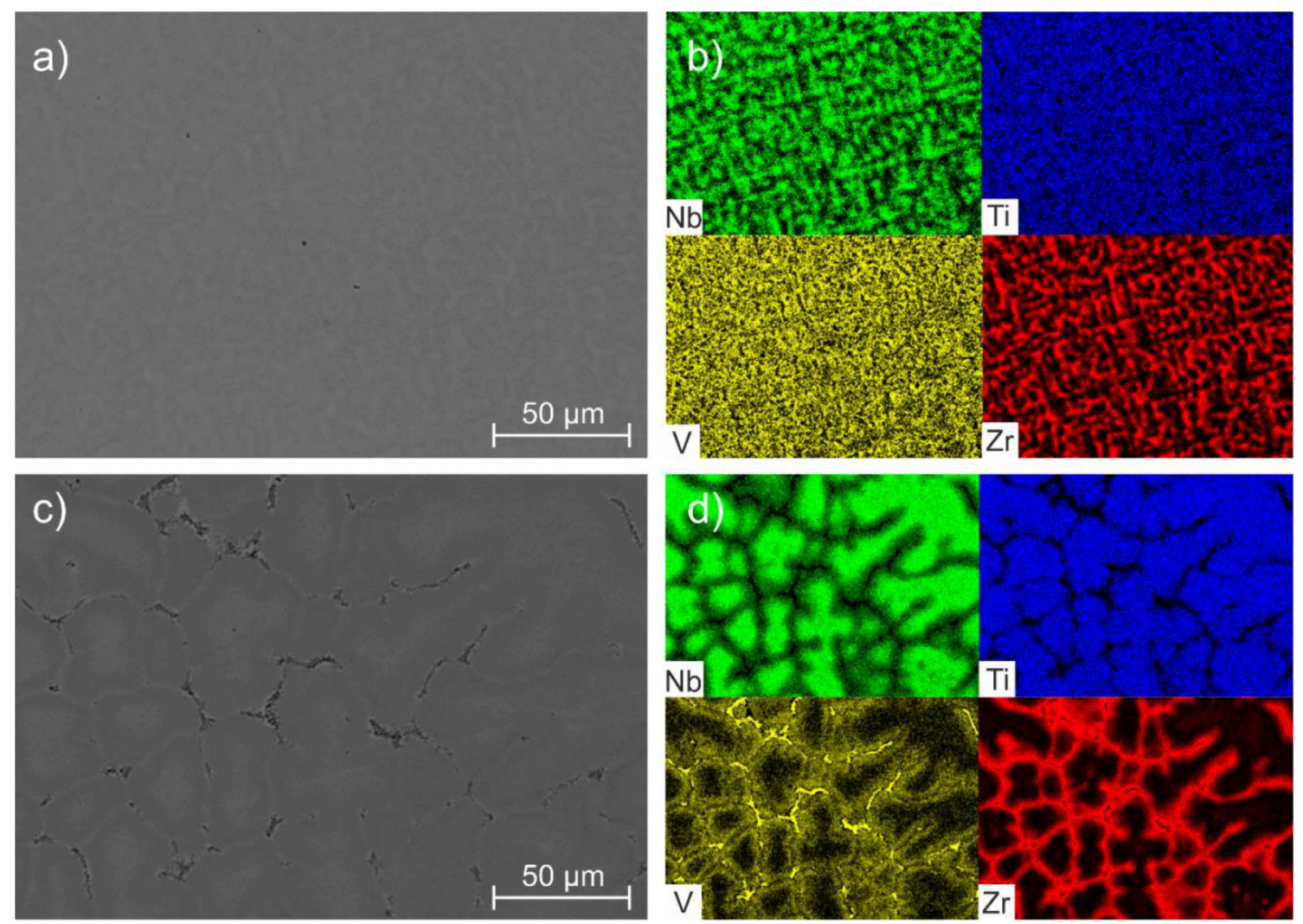

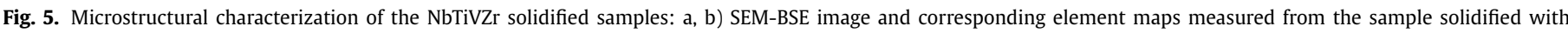
a melt undercooling $\Delta T=80 \mathrm{~K}$; c, d) SEM-BSE image and elemental maps measured from the sample solidified from the semisolid state.

(Fig. 1 and Table 2) as determined using the pyrometer in the EML device, is in good agreement (only $26 \mathrm{~K}$ lower) with the value predicted for equilibrium conditions by CALPHAD, as shown in Fig. 8 and Table 2. The liquidus temperature $T_{1}=1858 \pm 7 \mathrm{~K}$ is $68 \mathrm{~K}$ lower than that predicted by CALPHAD (Fig. 8 and Table 2). Usually $T_{\mathrm{S}}$ is much less dependent on heating rates and sample sizes than $T_{1}$ [23]. Considering the mean value of $T_{\mathrm{S}}$ and the standard deviation in Table 2, one can see a very good agreement with CALPHAD prediction. On the other hand, $T_{1}$ should be much more dependent on the heating rate and sample mass [23], but even so, the values are in reasonable agreement.

The in situ XRD patterns measured during crystallisation of the NbTiVZr liquid undercooled by $80 \mathrm{~K}$ in the present work (Fig. 1) show only peaks of one $b c c$ phase (bcc\#1). The microstructural and structural analysis (Figs. 5a and 6) further confirm a homogenous nature of the SPSS despite the microsegregation of $\mathrm{Zr}$ and $\mathrm{V}$ observed in the interdendritic regions (Fig. 5b).

The sequence of images in Fig. 4a reveals that multiple grains nucleate and grow in the undercooled melt simultaneously and that they collide as solidification progresses. It is obvious from the plot of the gray value versus time (Fig. $4 \mathrm{~b}$ ) that only one recalescence (quasi-adiabatic release of heat upon crystallization) occurs. Thus, considering the in situ XRD showed in Fig. 1, the crystallizing solid corresponds to the dendrites of a single bcc\#1 phase.

It is safe to conclude that the only transformation that occurred was from the liquid into a bcc\#1 SPPS when the melt was undercooled by $80 \mathrm{~K}$. This agrees with previous studies where a bcc SPSS was obtained by quenching of NbTiVZr alloy from the liquid state [8] or homogenized state [6]. A wide stability range of the primary bcc\#1 phase below $T_{1}$ also follows from the thermodynamic calculations (Fig. 8). Formation of a second bcc\#2 phase at equilib- rium conditions is predicted by CALPHAD calculations to occur via a spinodal decomposition, starting at $1041 \mathrm{~K}$.

When the NbTiVZr sample was cooled from the semisolid state, formation of three bcc phases were observed by in situ XRD measurements (Fig. 2). The two bcc phases were revealed at the grain boundaries of the primary bcc phase by the microstructure analysis of the soldified samples (Figs. 3b, 5c, and 7). From the onset temperatures of the $b c c \# 2$ and $b c c \# 3$ (Fig. 2b), which are respectively $245 \mathrm{~K}$ and $455 \mathrm{~K}$ below $T_{\mathrm{s}}$, one could conclude that they occurred as solid-state transformations. However, during nonequilibrium solidification constitutional undercooling may lead to an overall change in the composition of the remaining liquid. The interdendritic liquid then solidifies at a different $T_{\mathrm{S}}$ than the nominal alloy's composition. Furthermore, the pyrometer only measures a small surface area on the north pole of the droplet. It cannot distinguish temperature gradients over the sample and it does not probe local temperatures. The formation of bcc\#2 and bcc\#3 phases (Fig. 2) occurred during the final stage of solidification with crystallization of the interdendritic liquid. This is evident from the solidified microstructures shown in Figs. $5 \mathrm{c}$ and $5 \mathrm{~d}$. While the sample was cooled between $T_{1}$ and $T_{\mathrm{s}}$ solute partitioning from the primary dendrites (bcc\#1) to the interdendritic regions created the compositional conditions for their formation.

The ex situ XRD patterns (Figs. 3a and 3b) confirm that in both cases the phases formed at high temperature, as shown from the in situ XRD patterns in Figs. 1 and 2, are preserved at room temperature. The formation of equilibrium $h c p$ and C15-Laves phases which are predicted by CALPHAD (see Fig. 8) and have been experimentally observed after long-time annealing, at lower temperatures [6,7], were kinetically suppressed due to the fast cooling rate $\left(\sim 100 \mathrm{~K} \cdot \mathrm{s}^{-1}\right)$ in the solid-state. 


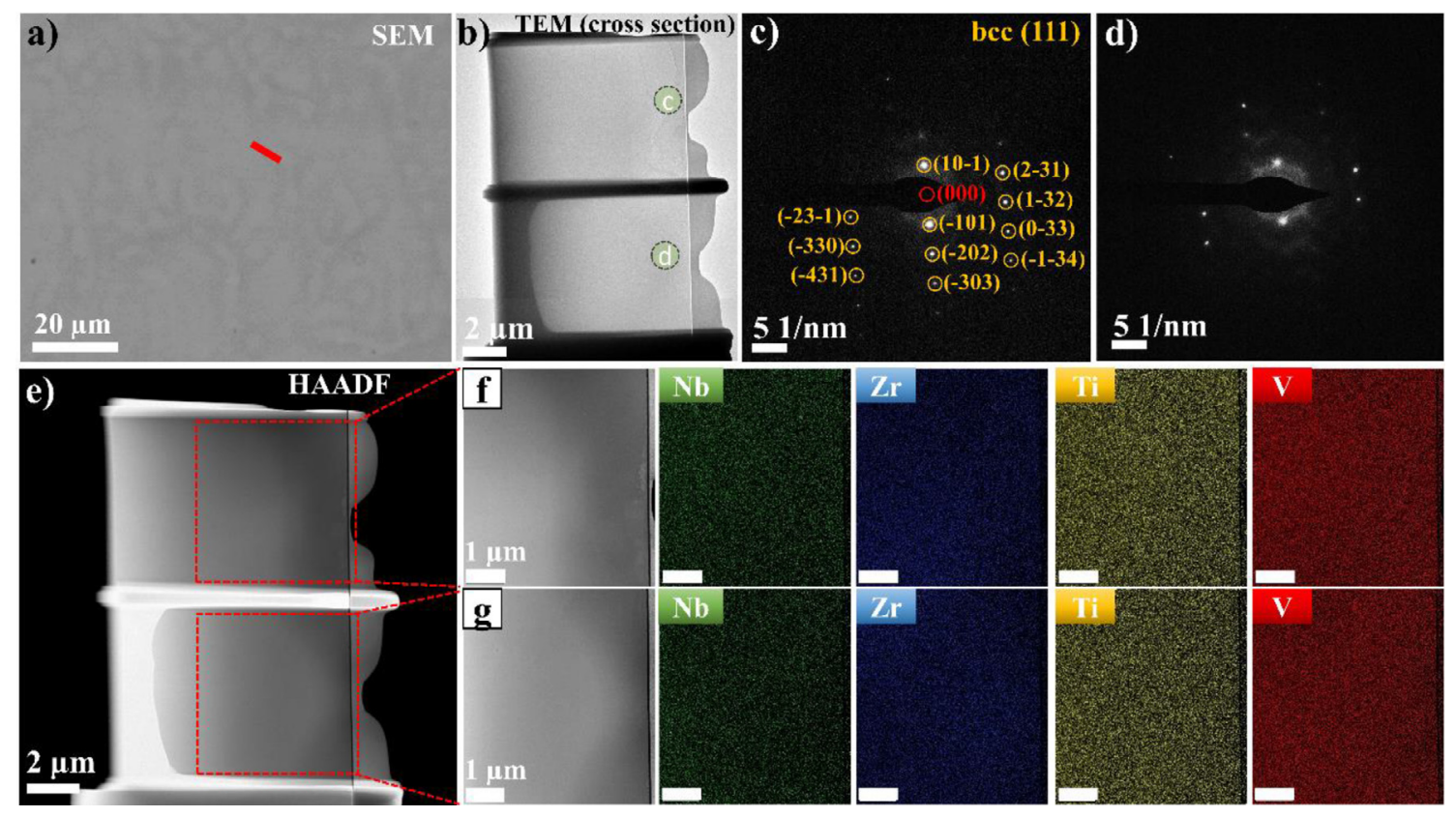

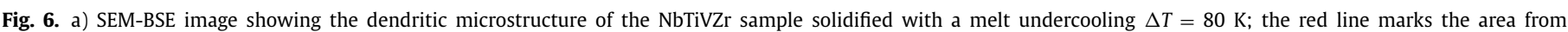

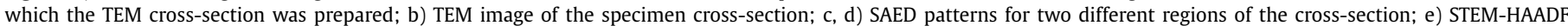

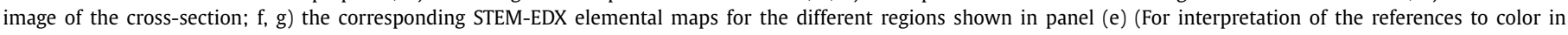
this figure legend, the reader is referred to the web version of this article).

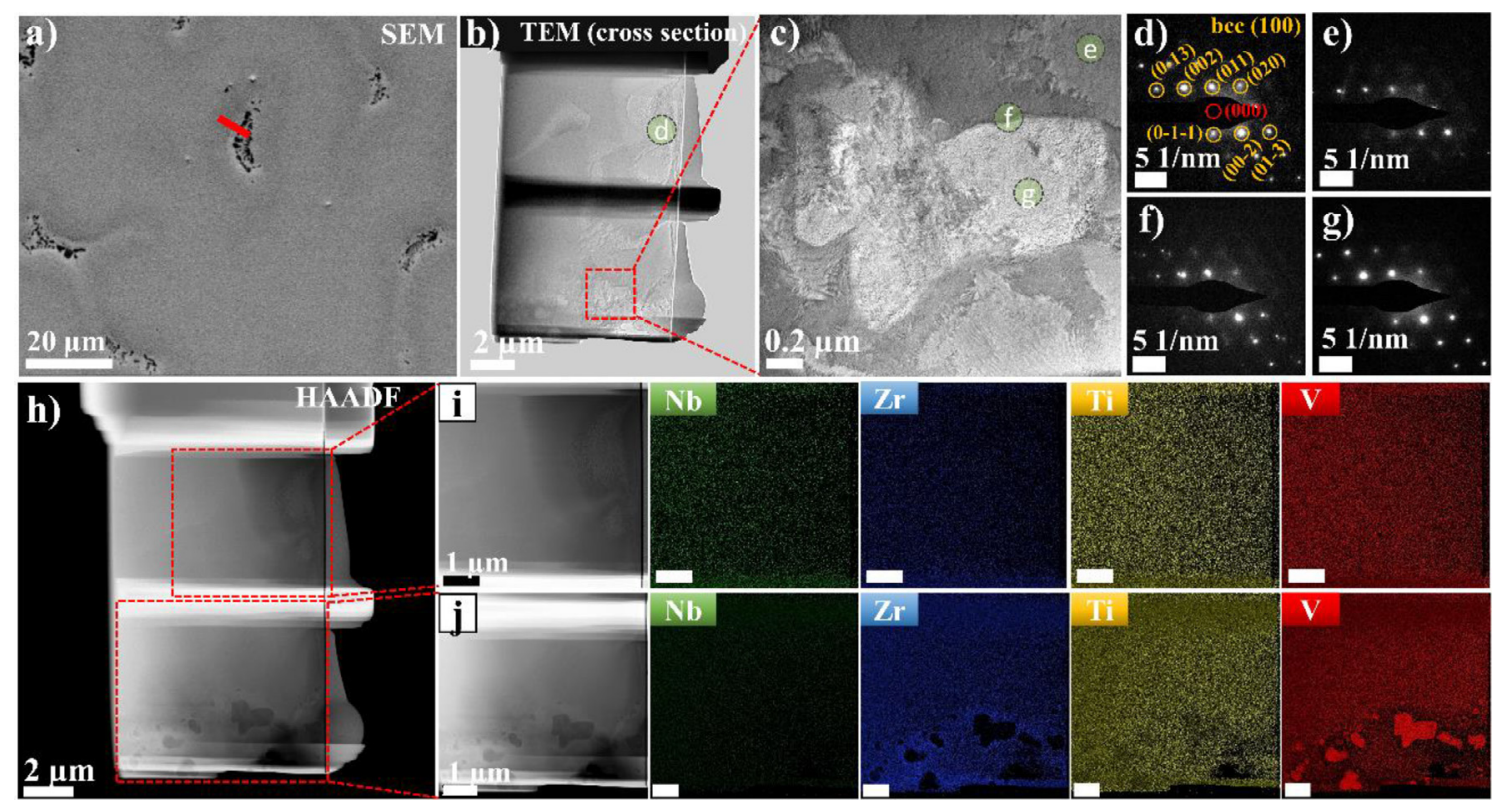

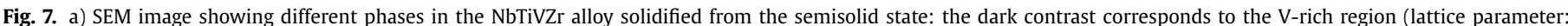

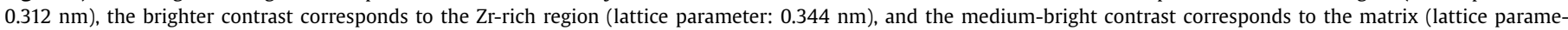

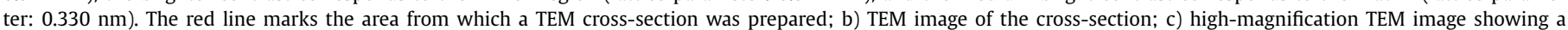

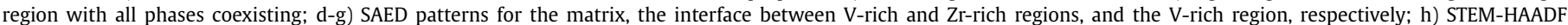

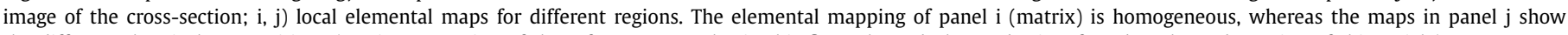
the different chemical compositions (For interpretation of the references to color in this figure legend, the reader is referred to the web version of this article).

In the quaternary $\mathrm{Nb}-\mathrm{Ti}-\mathrm{V}-\mathrm{Zr}$ system, three of the the six constituent binary systems ( $\mathrm{Ti}-\mathrm{V}, \mathrm{Nb}-\mathrm{Zr}$ and $\mathrm{Nb}-\mathrm{V}$ ) are characterized by a solid-state miscibility gap with a critical temperature in the vicinity of the equiatomic composition. Below the critical temperature, the primary $b c c$ phase decomposes into Ti-rich $b c c$ and $\mathrm{V}$-rich bcc (Ti-V system), Nb-rich bcc and Zr-rich bcc (Nb-Zr system), and $\mathrm{Nb}$-rich $b c c$ and $\mathrm{V}$-rich $b c c$ (Nb-V system). These constituent binaries contribute to the quaternary system such that theoretically at least three $b c c$ composition sets should exist: Nb- rich (bcc\#1), V-rich (bcc\#2) and (Zr,Ti)-rich bcc\#3 (Zr- and Ti-rich $b c c$ combines due to unlimited solid solubility of $\mathrm{Zr}$ in $\mathrm{Ti}$ and vice versa).

Non-equilibrium solidification of the NbTiVZr alloy calculated using the Scheil-Gulliver model is shown in Fig. 9. The solidification proceeds between $T_{1}=1926 \mathrm{~K}$, which is the same as for the equilibrium conditions, and a eutectic temperature $T_{\mathrm{e}} \approx 1491 \mathrm{~K}$ at what the fraction of the liquid phase decreases to about $1 \%$. The temperature dependences for the compositions of the liquid and 


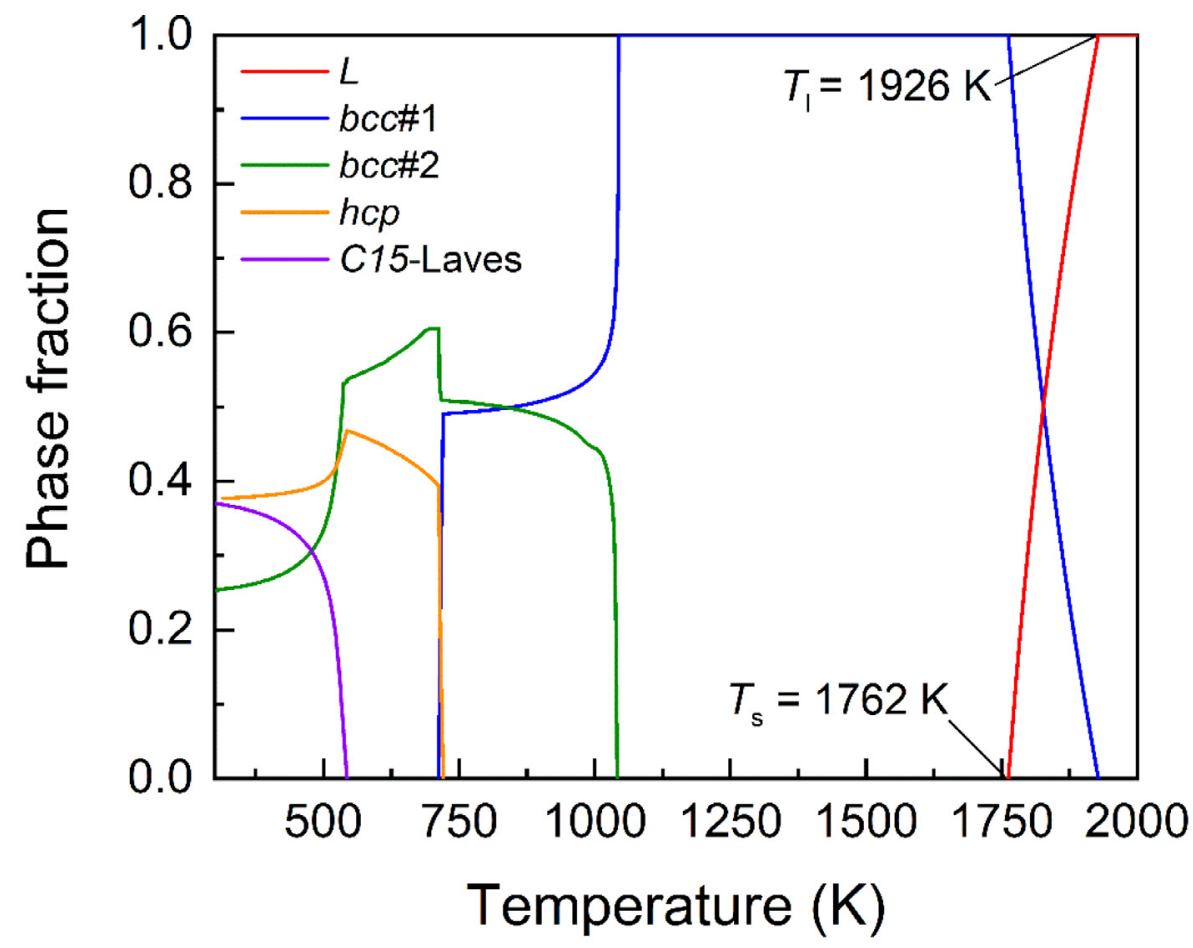

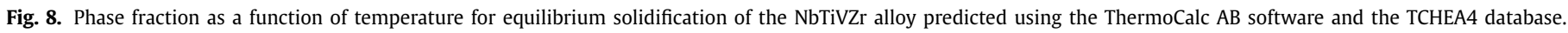

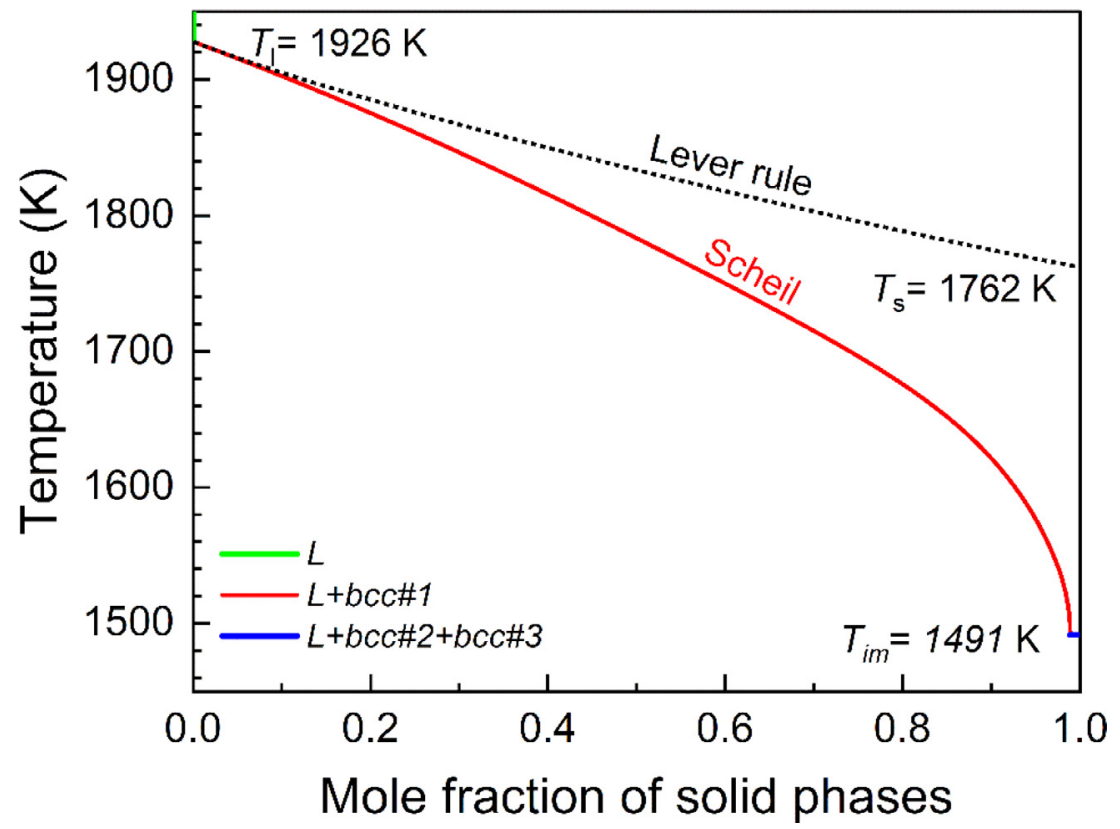

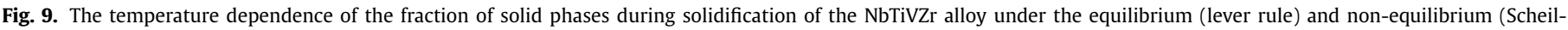
Gulliver) conditions simulated with the ThermoCalc AB software using the TCHEA4 database.

the solid phases are shown in Fig. 10. The Scheil-Gulliver simulation suggests that cores of the $b c c \# 1$ dendrites formed in earlier stage of solidification are enriched with $\mathrm{Nb}$ and Ti (Fig. 10b, $T$ above $\sim 1770 \mathrm{~K}$ ). Upon cooling, both $\mathrm{V}$ and $\mathrm{Zr}$ continuously segregate into the interdendritic liquid (Fig. 10a) and start to dominate in the peripheral areas of the dendrites (Fig. 10b, $T$ below $\sim 1735$ $\mathrm{K})$. Below $1492 \mathrm{~K}$, the interdendritic liquid solidifies into the Vrich bcc\#2 and a $\mathrm{Zr}$-rich bcc\#3 phases via eutectic reaction which completely finishes at $1491 \mathrm{~K}$. These results agree with the element distribution maps presented in Fig. 5d and in Fig. S3 in Supplementary Material. Also, such solidification path conforms with the in-situ XRD measurement upon solidification of the NbTiVZr alloy from the semisolid state (Fig. 2). In that case, the (110) reflections of a V-rich phase was observed to appear at $1491 \mathrm{~K}$. The (110) peak of a $\mathrm{Zr}$-rich phase was noticed at a lower temperature $(1281 \mathrm{~K})$. The discrepancy on the formation of the metastable bcc phases between the Scheil-Gulliver calculation and in-situ XRD measurements could be explained either by some deviation of the real and simulated solidification paths or by somewhat imperfect modelling of the TCHEA4 database (see for this also our previous papers $[17,24])$, or by experimental uncertainty. Indeed, the molar fraction of the $b c c \# 2$ and $b c c \# 3$ phases is very small and they 
a)

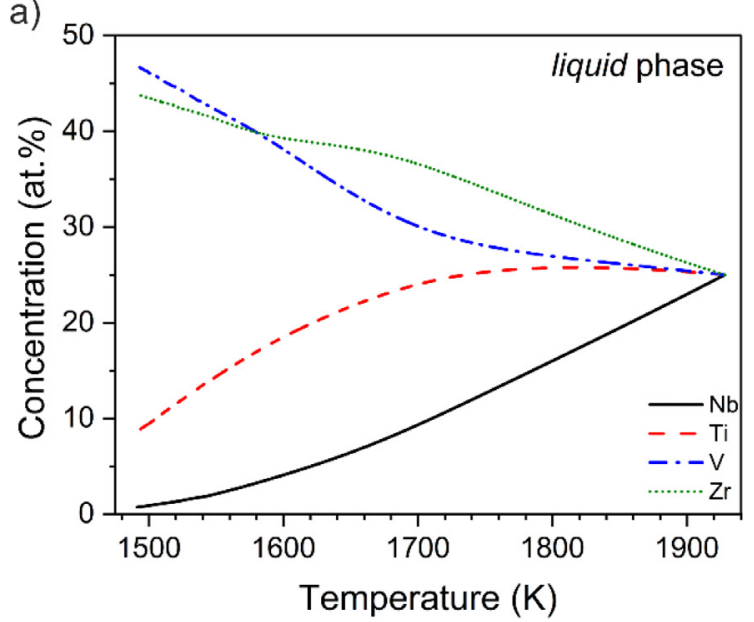

c)

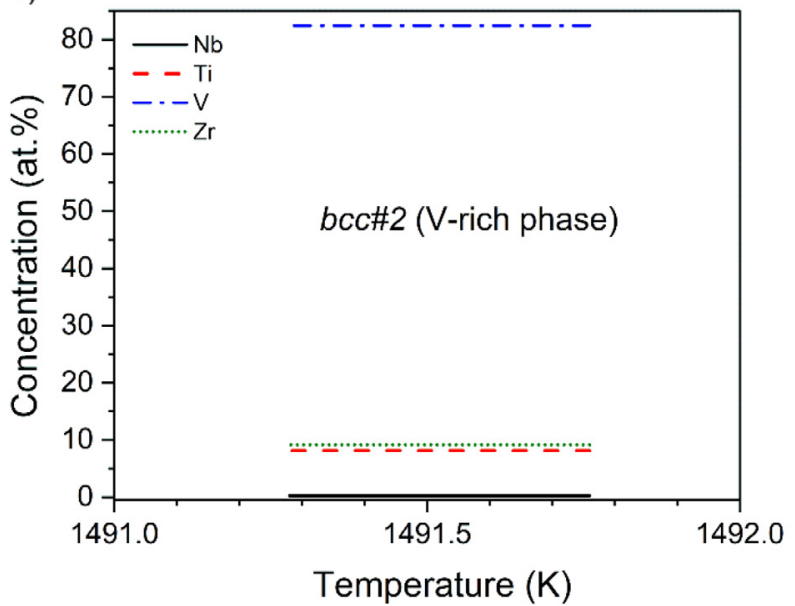

b)

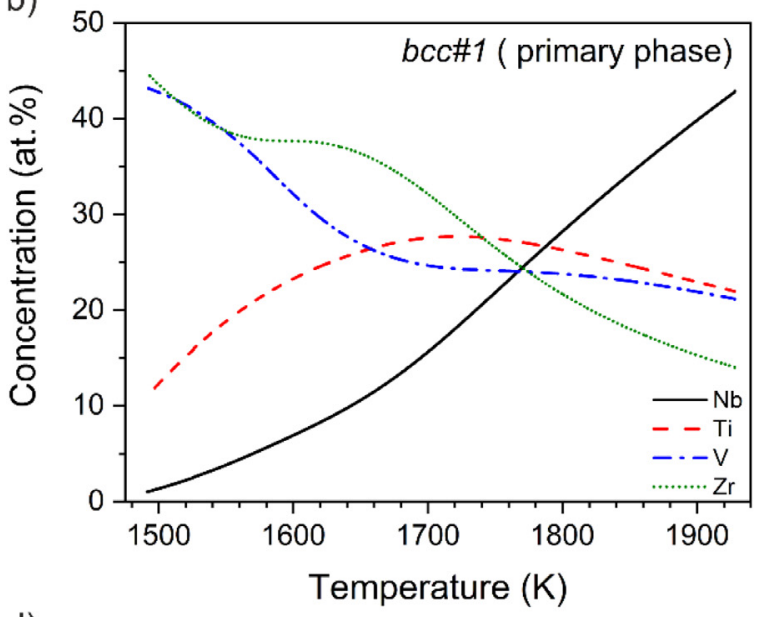

d)

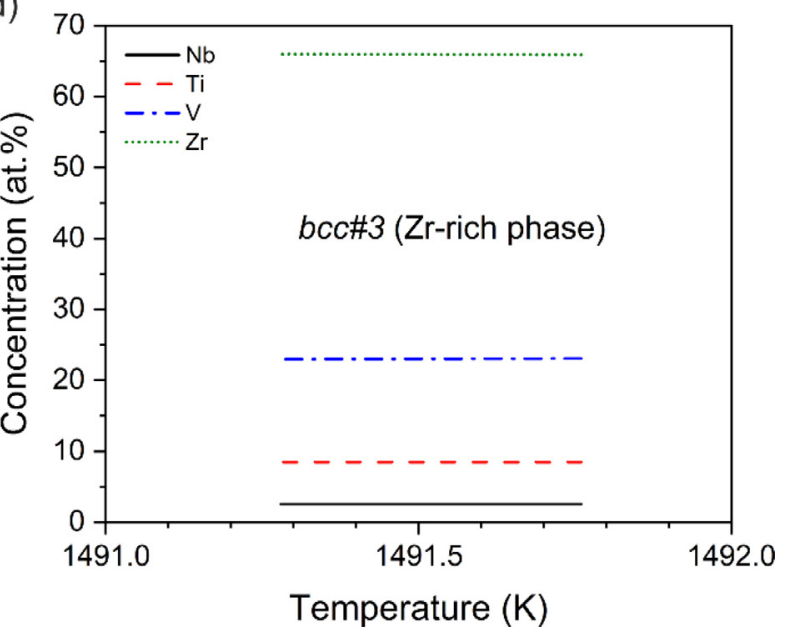

Fig. 10. Composition of the liquid and solid phases predicted by Scheil-Gulliver solidification simulation of NbTiVZr.

Table 3

Crystal growth velocity $v$ as a function of melt undercooling $\Delta T$ upon crystallization of the NbTiVZr RHEA.

\begin{tabular}{ll}
\hline$\Delta T(\mathrm{~K})$ & $v\left(\mathrm{~m} \cdot \mathrm{s}^{-1}\right)$ \\
\hline 77 & $\sim 0.009$ \\
101 & $\sim 0.015$ \\
107 & $\sim 0.017$ \\
112 & $\sim 0.019$ \\
145 & $\sim 0.037$ \\
\hline
\end{tabular}

can be noticed on XRD patterns only when they reach a detectable quantity at the X-ray beam position.

\subsection{Crystal growth kinetics}

It can be seen from the high-speed video of the crystallizing NbTiVZr melt at $107 \mathrm{~K}$ undercooling (Video 1 in Supplementary Materials), as well as from the selected digital images in Fig. 4 that the crystal growth velocity $v$ is extremely low. The values of $v$ extracted from the digital videos taken after different melt undercooling are given in Table 1 . The largest $v$-value, measured at 145 $\mathrm{K}$, is equal just to about $0.04 \mathrm{~m} \cdot \mathrm{s}^{-1}$. Table 3

It is known that the growth velocity of $b c c$ crystals is in general smaller than that of $f c c$ crystals. For example it has been shown in a recent study of Andreoli et al. [17] that $v_{\text {bcc }}$ is about 3 - 4 times smaller than $v_{\text {fcc }}$ in the CoCrFeNi HEA at $\sim 80 \mathrm{~K}$ undercooling, relative to the liquidus temperature of the respective phase. However, the growth velocity of the bcc phase in the undercooled $\mathrm{CoCrFeNi}$ melt is about two orders of magnitude larger than in the NbTiVZr melt. For compatison, $v_{\text {bcc }}$ is equal to $\sim 1.15 \mathrm{~m} \cdot \mathrm{s}^{-1}$ at $\Delta T=80 \mathrm{~K}$ in CoCrFeNi and $\sim 0.01 \mathrm{~m} \cdot \mathrm{s}^{-1}$ at $\Delta T=77 \mathrm{~K}$ in NbTiVZr.

Wang et al. [25] have recently studied the solidification of electrostatically levitated NbMoTaWZr refractory HEA and reported a growth velocity for the $b c c$ phase of $0.23 \mathrm{~m} \cdot \mathrm{s}^{-1}$ for $\Delta T=82 \mathrm{~K}$. This is also very low growth rate. Yet, it is about one order of magnitude larger than that obtained for the NbTiVZr alloy at a similar undercooling in the present study.

Probably the difference in the growh velocities of the $b c c$ phases in NbTiVZr and NbMoTaWZr can be explained to some extent by the different methods used for their determination. In Ref. [25] the growth velocity was measured by the infrared method as the ratio of the sample diameter to the recalescence time. In the present work, it is calculated from the crystallisation front propagation over time using high-speed video. It is, however, quite plausible that the crystal growth kinetics of the NbTiVZr alloy is indeed sluggisher than that of the NbMoTaWZr, at least at relatively low undercooling, as in the present study, where the solidification is diffusion-controlled. For example, it has been shown by Vaidya et al. [26,27] that the diffusion rate in HEAs, in the solid-state, does not necessarily decrease with increasing number of alloy constituents $N$ as it has been supposed in the first publications on HEAs.

\subsection{Microstructural features}

At a very low undercooling, which must be the case when the melt was slowly cooled from the semisolid state (Fig. 2), constitu- 
tional undercooling is dominant. At this level of undercooling the dendrite tip is capable of coarsening which can lead to coarser microstructures. This is observed when comparing the dendritic structures shown in Figs. 5a and 5c. Crystal growth velocity should be very limited which also contributes to coarsening of the microstructure. Unfortunately, the visualization of the solidification when samples are processed in this manner cannot be done because of the extremely weak contrast between the liquid and the crystalline phase due to a small release of latent heat. Under these conditions, solute rejection occurring at the solid/liquid interface has had sufficient time to result in partitioning which is evident from the interdendritic regions in Figs. $5 c$ and $5 d$. Contrarily, the microstructure of the sample solidified under an undercooling of $80 \mathrm{~K}$ revealed a much finer dendritic structure and less microsegregation (Figs. 5a and 5b). At a moderate undercooling, such as $\Delta T=80 \mathrm{~K}$, the decrease of dendrite tip and faster crystal growth kinetics lead to smaller dendrites (Fig. 5a).

\section{Conclusions}

The initial state and solidification kinetics plays a central role in the high-temperature phase formation of the NbTiVZr RHEA. While a $b c c$ single-phase microstructure was formed when the liquid was undercooled over $80 \mathrm{~K}$, solidification from the semisolid state between $T_{1}$ and $T_{\mathrm{S}}$ lead to the development of a multi-phase microstructure. In the first case, as the driving force for crystallization is proportional to the liquid undercooling, a non-equilibrium solidification is established with (relatively) higher crystal growth rates which were evident from the fine solidified microstructure. In the latter case, with negligible undercooling, a coarse dendritic microstructure was formed with intense microsegregation of vanadium and zirconium into the interdendritic regions and appearance of two additional bcc phases at the grain boundaries.

The solute microsegregation and formation of the bcc\#2 and bcc\#3 phases could be explained by Scheil-Gulliver solidification that was simulated by the CALPHAD approach using the TCHEA4 database. The discrepancy on the onset temperature for the formation of the bcc\#3 phase between CALPHAD prediction and experiment can be explained either by deviation of the real and simulated solidification paths, somewhat imperfect modelling of the TCHEA4 database or experimental uncertainty.

The growth velocity of the primary $b c c$ phase in the NbTiVZr alloy is found to be about one order of magnitude smaller than that of the NbMoTaWZr alloy at a similar undercooling reported in the literature.

\section{Declaration of Competing Interest}

The authors declare that they have no known competing financial interests or personal relationships that could have appeared to influence the work reported in this paper.

\section{Acknowledgments}

AFA acknowledges the financial support of the Ph.D. work at the Leibniz IFW Dresden by the Brazilian Federal Agency for Support and Evaluation of Graduate Education CAPES (grant number: $88887.161381 / 2017-00,2017)$ in the frame of CAPES/DAAD/CNPq International Cooperation Program. OS acknowledges the financial support by the German Space Agency DLR under contract 50WM1546. MvH acknowledges funding from the ERC-CoG grant NANO-INSITU (Grant No. 683076). Parts of this research were carried out at the light source PETRA III, beamline P21.1 at DESY, a member of the Helmholtz Association (HGF). We acknowledge 0. Ivashko, A-C Dippel, and M. v. Zimmermann for the support of the diffraction measurements at the beamline P21.1. The authors thank
A. Voß for the chemical analysis and J. Werner for the DTA measurements.

\section{Supplementary materials}

Supplementary material associated with this article can be found, in the online version, at doi:10.1016/j.actamat.2021.117416.

\section{References}

[1] O.N. Senkov, D.B. Miracle, K.J. Chaput, J.-P. Couzinie, Development and exploration of refractory high entropy alloys-A review, J. Mater. Res. 33 (2018) 1-37, doi:10.1557/jmr.2018.153.

[2] O.N. Senkov, S.V. Senkova, C. Woodward, D.B. Miracle, Low-density, refractory multi-principal element alloys of the $\mathrm{Cr}-\mathrm{Nb}-\mathrm{Ti}-\mathrm{V}-\mathrm{Zr}$ system: Microstructure and phase analysis, Acta Mater 61 (2013) 1545-1557, doi:10.1016/j.actamat. 2012.11.032.

[3] O.N. Senkov, S. Rao, K.J. Chaput, C. Woodward, Compositional effect on microstructure and properties of NbTiZr-based complex concentrated alloys, Acta Mater 151 (2018) 201-215, doi:10.1016/j.actamat.2018.03.065.

[4] Y. Jia, L. Zhang, P. Li, X. Ma, L. Xu, S. Wu, Y. Jia, G. Wang, Microstructure and Mechanical Properties of Nb-Ti-V-Zr Refractory Medium-Entropy Alloys, Front. Mater. 7 (2020) 1-11, doi:10.3389/fmats.2020.00172.

[5] O.N. Senkov, S.V. Senkova, D.B. Miracle, C. Woodward, Mechanical properties of low-density, refractory multi-principal element alloys of the $\mathrm{Cr}-\mathrm{Nb}-\mathrm{Ti}-\mathrm{V}-\mathrm{Zr}$ system, Mater. Sci. Eng. A. 565 (2013) 51-62, doi:10.1016/j.msea.2012.12.018.

[6] D.J.M. King, S.T.Y. Cheung, S.A. Humphry-Baker, C. Parkin, A. Couet, M.B. Cortie, G.R. Lumpkin, S.C. Middleburgh, A.J. Knowles, High temperature, low neutron cross-section high-entropy alloys in the Nb-Ti-V-Zr system, Acta Mater 166 (2019) 435-446, doi:10.1016/j.actamat.2019.01.006.

[7] N. Yurchenko, N. Stepanov, M. Tikhonovsky, G. Salishchev, Phase Evolution of the AlxNbTiVZr ( $\mathrm{x}=0 ; 0.5 ; 1 ; 1.5)$ High Entropy Alloys, Metals (Basel) 6 (2016) 298, doi: $10.3390 /$ met6120298.

[8] Y. Tong, S. Zhao, H. Bei, T. Egami, Y. Zhang, F. Zhang, Severe local lattice distortion in $\mathrm{Zr}$ - and/or Hf-containing refractory multi-principal element alloys, Acta Mater 183 (2020) 172-181, doi:10.1016/j.actamat.2019.11.026.

[9] F. He, Z. Wang, Q. Wu, J. Li, J. Wang, C.T.T. Liu, Phase separation of metastable $\mathrm{CoCrFeNi}$ high entropy alloy at intermediate temperatures, Scr. Mater. 126 (2017) 15-19, doi:10.1016/j.scriptamat.2016.08.008.

[10] Q. Tang, Y. Huang, H. Cheng, X. Liao, T.G. Langdon, P. Dai, The effect of grain size on the annealing-induced phase transformation in an $\mathrm{Al0} \cdot 3 \mathrm{CoCrFeNi}$ high entropy alloy, Mater. Des. 105 (2016) 381-385, doi:10.1016/j.matdes.2016.05. 079.

[11] G. Laplanche, S. Berglund, C. Reinhart, A. Kostka, F. Fox, E.P. George, Phase stability and kinetics of $\sigma$-phase precipitation in $\mathrm{CrMnFeCoNi}$ high-entropy alloys, Acta Mater 161 (2018) 338-351, doi:10.1016/j.actamat.2018.09.040.

[12] E.J. Pickering, R. Muñoz-Moreno, H.J. Stone, N.G. Jones, Precipitation in the equiatomic high-entropy alloy CrMnFeCoNi, Scr. Mater. 113 (2016) 106-109, doi:10.1016/j.scriptamat.2015.10.025.

[13] H. Jiang, R.I. Gomez-Abal, P. Rinke, M. Scheffler, Electronic band structure of zirconia and hafnia polymorphs from the GW perspective, Phys. Rev. B. 81 (2010) 085119, doi:10.1103/PhysRevB.81.085119.

[14] O. Shuleshova, I. Kaban, W. Loser, S. Ziller, U. Reinhold, D. Lindackers, Metastable phase formation in undercooled Fe-Co melts under terrestrial and microgravity conditions, IFW Dresden, Annu. Rep. (2017) 39-42 https://www. ifw-dresden.de/uploads/users/10/uploads/files/JB_2017.pdf.

[15] A.P. Hammersley, S.O. Svensson, M. Hanfland, A.N. Fitch, D. Hausermann, D. Häusermann, Two-dimensional detector software: From real detector to idealised image or two-theta scan, High Press. Res. 14 (1996) 235-248, doi:10. 1080/08957959608201408

[16] J. Schindelin, I. Arganda-Carreras, E. Frise, V. Kaynig, M. Longair, T. Pietzsch, S. Preibisch, C. Rueden, S. Saalfeld, B. Schmid, J.-Y. Tinevez, D.J. White, V. Hartenstein, K. Eliceiri, P. Tomancak, A. Cardona, Fiji: an open-source platform for biological-image analysis, Nat. Methods. 9 (2012) 676-682, doi:10. 1038/nmeth.2019.

[17] A.F. Andreoli, O. Shuleshova, V.T. Witusiewicz, Y. Wu, Y, Yang, O. Ivashko, A.-C. Dippel, M.v. Zimmermann, K. Nielsch, I. Kaban, In situ study of nonequilibrium solidification of CoCrFeNi high-entropy alloy and CrFeNi and CoCrNi ternary suballoys, Acta Mater 212 (2021) 116880, doi:10.1016/j.actamat. 2021.116880.

[18] J. Thomas, T. Gemming, ELDISCA C\# - a new version of the program for identifying electron diffraction patterns, in: W.T. Luysberg M., Tillmann K. (Ed.), EMC 2008 14th Eur. Microsc. Congr. 1-5 Sept. 2008, Aachen, Ger., Springer Berlin Heidelberg, Berlin, Heidelberg, 2008: pp. 231-232. doi:10.1007/978-3540-85156-1_116.

[19] T. Degen, M. Sadki, E. Bron, U. König, G. Nénert, The high score suite, Powder Diffr (2014), doi:10.1017/S0885715614000840.

[20] T.J.B. Holland, S.A.T. Redfern, UNITCELL: A nonlinear least-squares program for cell-parameter refinement implementing regression and deletion diagnostics, J. Appl. Crystallogr. (1997), doi:10.1107/S0021889896011673.

[21] Thermo-Calc AB Software, (2020). https://thermocalc.com/.

[22] H.-L. Chen, H. Mao, Q. Chen, Database development and Calphad calculations for high entropy alloys: Challenges, strategies, and tips, Mater. Chem. Phys. 210 (2018) 279-290, doi:10.1016/j.matchemphys.2017.07.082. 
[23] M. Žaludová, B. Smetana, S. Zlá, J. Dobrovská, K. Gryc, K. Michalek, R. Dudek, Study of DTA method experimental conditions and of their influence on obtained data of metallic systems, in: Met. 2012 - Conf. Proceedings, 21st Int. Conf. Metall. Mater, 2012, pp. 640-645.

[24] O. Stryzhyboroda, V.T. Witusiewicz, S. Gein, D. Röhrens, U. Hecht, Phase Equilibria in the Al-Co-Cr-Fe-Ni High Entropy Alloy System: Thermodynamic Description and Experimental Study, Front. Mater. 7 (2020), doi:10.3389/fmats. 2020.00270.

[25] W.L. Wang, L. Hu, S.J. Yang, A. Wang, L. Wang, B. Wei, Liquid Supercoolability and Synthesis Kinetics of Quinary Refractory High-entropy Alloy, Sci. Rep. 6 (2016) 1-7, doi:10.1038/srep37191.
[26] M. Vaidya, K.G. Pradeep, B.S. Murty, G. Wilde, S.V. Divinski, Bulk tracer diffusion in CoCrFeNi and CoCrFeMnNi high entropy alloys, Acta Mater 146 (2018) 211-224, doi:10.1016/j.actamat.2017.12.052.

[27] M. Vaidya, G.Mohan Muralikrishna, S.V. Divinski, B.S. Murty, Experimental assessment of the thermodynamic factor for diffusion in $\mathrm{CoCrFeNi}$ and $\mathrm{CoCr}$ FeMnNi high entropy alloys, Scr. Mater. 157 (2018) 81-85, doi:10.1016/j. scriptamat.2018.07.040. 